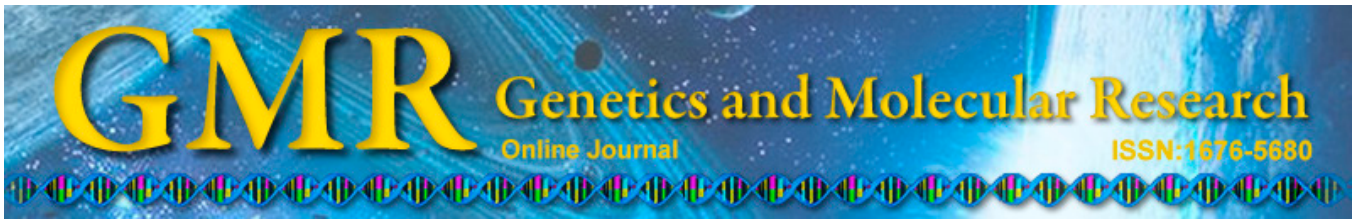

\title{
Effects of VEGF/VEGFR/K-ras signaling pathways on miRNA21 levels in hepatocellular carcinoma tissues in rats
}

\author{
J.Z. Gao ${ }^{1,2 *}$, Y.L. Wang ${ }^{1 *}$, J. Li $^{2}$ and L.X. Wei ${ }^{2}$ \\ ${ }^{1}$ Medical College, Xinxiang Medical University, Xinxiang, \\ Henan Province, China \\ ${ }^{2}$ Department of Pathology, General Hospital of the People's Liberation Army, \\ Beijing, China \\ *These authors contributed equally to this study. \\ Corresponding author: L.X. Wei \\ E-mail: weilx301@263.net
}

Genet. Mol. Res. 14 (1): 671-679 (2015)

Received July 8, 2014

Accepted December 5, 2014

Published January 30, 2015

DOI http://dx.doi.org/10.4238/2015.January.30.10

\begin{abstract}
The aim of this study was to investigate the effects of the vascular endothelial growth factor (VEGF)/VEGF receptor (VEGFR)/ K-ras signaling pathways on miRNA21 levels in hepatocellular carcinoma tissues in rats. Eighteen male Sprague-Dawley rats were randomly divided into normal control, model, and VEGF blocking agent groups ( $\mathrm{N}=6$ /group). The expression of $V E G F$ mRNA, K-ras protein, and miRNA21 increased significantly $(\mathrm{P}<0.05)$ in the model group compared with the normal control group, and decreased dramatically in the VEGF blocking agent group compared to the model group. The expression of $V E G F R$ mRNA in the model group was higher than that of the control group, and the expression of VEGFR mRNA in the VEGF blocking agent group was significantly higher than that of the control group $(\mathrm{P}<0.05)$. Statistically, there was no difference between the expression of VEGFR mRNA for the VEGF blocking agent group and the model group $(\mathrm{P}>0.05)$. Finally, the expression of the miRNA21
\end{abstract}


gene in the VEGF blocking agent group was higher than in the control group, and there was a significant statistical difference noted; Pearson's correlation analysis demonstrated that the expression of K-ras protein was positively correlated with miRNA21 in the experimental groups $(\mathrm{P}=0.001)$. The above results showed that the VEGF/VEGFR/K-ras signaling pathway might promote the occurrence and development of hepatocellular carcinoma cells through regulating expression of miRNA21, which has potential clinical value for the development of therapies against biological targets and determining prognosis for patients with hepatocellular carcinoma.

Key words: Hepatocellular carcinoma; Vascular endothelial growth factor; K-ras; miRNA21

\section{INTRODUCTION}

The growth, invasion, and metastasis of malignant tumor cells depend on the growth of blood vessels in tumors. Activation of signaling transduction pathways of vascular endothelial growth factor (VEGF) and its receptor (VEGFR) can stimulate the proliferation and migration of endothelial cells, playing an important role in the occurrence, development, invasion, and metastasis of hepatocellular carcinoma (HCC) (Meng et al., 2013). MicroRNA (miRNA) is a type of endogenous non-coding single chain RNA reaching a length of 20-22 nucleotides (nt). Investigations have found abnormal, positive miRNA expression in human HCC tissues (Hu et al., 2013). The present study explores the effects of VEGF/VEGFR/K-ras-related signaling pathways on miRNA21 levels in HCC tissues in rats. Here, we utilized the hepatoma rat model in order to provide both theoretical and experimental bases for the occurrence and development of HCC and the development of a biological therapy target.

\section{MATERIAL AND METHODS}

\section{Ethics statement}

This study was approved by the XinXiang University Animal Care and Use Committee.

\section{Establishment of a rat model of HCC}

Eighteen male Sprague-Dawley (SD) rats (150-180 g body weight) were used in this experiment. Animals were provided by the Experimental Animal Center of Henan Province. The rat models of HCC were established according to the method reported by Futakuchi et al. (1999). Twelve SD rats were administered $70 \mathrm{mg} / \mathrm{kg}$ diethylnitrosamine aqueous solution intragastrically once a week for 18 weeks. The 12 rats were randomly divided into group B, the hepatocellular carcinoma model group (Figure 1), and group C, the VEGF blocking agent group, with six rats in each group. For group C, $0.003 \mathrm{~mL} / \mathrm{g}$ VEGF blocking agent was administered by intraperitoneal injection once every two weeks for four continuous weeks from the 10th week. Group A, the normal control group, was composed of six rats (Figure 2). The rats in every experimental group were terminated in the 18th week. Once deceased, a piece of liver 
tissue from each rat was collected and kept in liquid nitrogen. The frozen tissues were stored in refrigeration at $-80^{\circ} \mathrm{C}$.

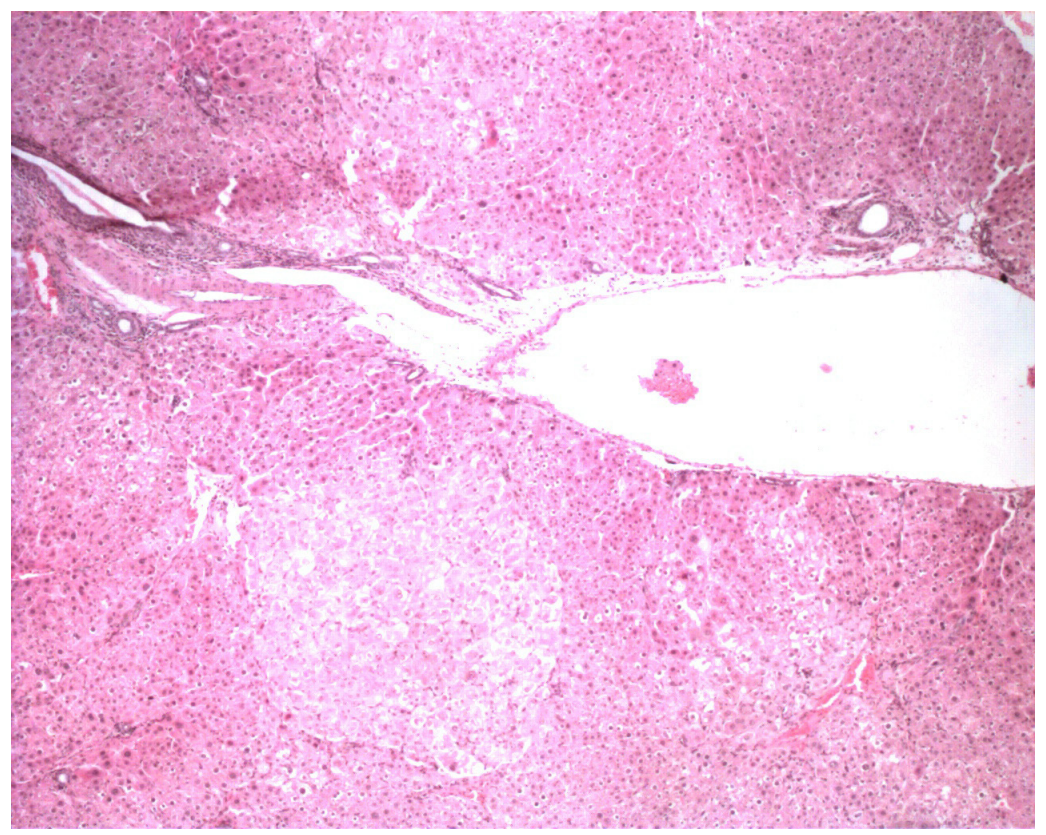

Figure 1. Representative hematoxylin and eosin staining of the hepatocellular carcinoma model group (200X).

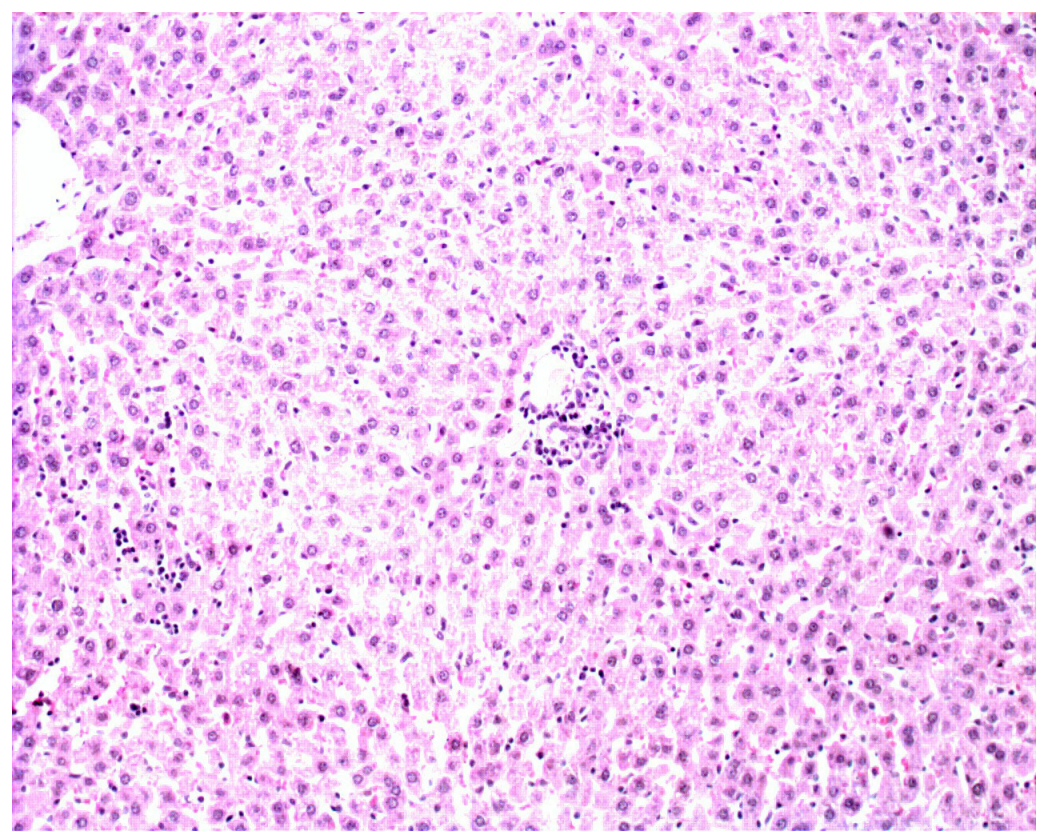

Figure 2. Representative hematoxylin and eosin staining of the normal control group (200X). 


\section{RNA extraction and fluorescence quantitative real-time polymerase chain reaction (RT-PCR) analysis}

Fluorescence quantitative RT-PCR (ABI 7500) was used to detect the expression level of $V E G F, V E G F R$, and miRNA21. Total RNA was extracted from tissue samples using Trizol reagent (Invitrogen) according to the manufacturer instructions. Two microgram RNA was reversely transcribed using the TransScript and cDNA Synthesis Kit (CWbio Co. Ltd.). PCR primers were designed and synthesized by the Beijing Sainuobo Biotechnology Center (Beijing, China). $\beta$-actin was used as an internal control for normalization. The sequences of the PCR primers were: $V E G F$ : forward 5'-CCG TCC TGT GTG CCC CTA ATG-3' and reverse 5'-CGC ATG ATC TGC ATA GTG ACG TTG-3'; VEGFR: forward 5'-GTG AGC GAT GTG GAA GGA GGC-3' and reverse 5'-CGA TGA ATG CAC TTT CTG GAG GA-3'; $\beta$-actin: forward 5'-TGG AGT CTA CTG GCGTCTT-3' and reverse 5'-TGTCATATTTCTCGTGGTTCA-3'. The primer for human hsa-miR-21-5p was 5'-TAG CTT ATC AGA CTG ATG TTG A-3' and for miRNU6-2 (internal U6) was: 5'-CTG CGC AAG GAT GAC ACG C-3'. Reaction conditions were performed at $95^{\circ} \mathrm{C}$ for $10 \mathrm{~min}$, and then at $95^{\circ} \mathrm{C}$ for $15 \mathrm{~s}$ followed by $60^{\circ} \mathrm{C}$ for $60 \mathrm{~s}$, for 45 cycles. Each reaction was repeated three times. Ultra SYBR Mixture (with ROX) (CWbio Co. Ltd.) was used in the amplification reaction. The differences in mRNA expression were compared using the relative quantitative method: normal liver tissue served as a control; thus, relative expression of a gene based on cycle threshold $(\mathrm{Ct})$ could be calculated using the $\mathrm{Ct}$ value of the internal gene. The equation is: $\Delta \Delta \mathrm{Ct}=\left(\mathrm{Ct}_{\text {target }}\right.$ gene $\left.\mathrm{Ct}_{\mathrm{ACTB}}\right)$ hepatocellular carcinoma tissue - $\left(\mathrm{Ct}_{\text {objective gene }}-\mathrm{Ct}_{\mathrm{ACTB}}\right)$ liver tissue in the control group, and values of $2^{-\Delta \Delta C t}$ were calculated.

\section{Detection of K-ras expression by Western blot}

Tissue samples were cut into pieces and incubated with lysis buffer at $4^{\circ} \mathrm{C}$ overnight. Concentrations of proteins were determined by the Coomassie brilliant blue staining method. An equal amount of protein was taken from each group; polyacrylamide gel electrophoresis was used for protein separation, and the gels were then transferred to polyvinylidene fluoride membrane. Dried skimmed milk solution was employed in blocking the membranes for $4 \mathrm{~h}$, and membranes were incubated with the anti-K-ras primary antibody (Santa Cruz Technology, Santa Cruz, CA, USA) overnight at $4^{\circ} \mathrm{C}$ at a dilution of 1:20,000. The following day, the membranes were incubated with the secondary antibody at room temperature for $2 \mathrm{~h}$. Developing (enhanced chemiluminescent), exposure, film scanning, and quantitative analysis were conducted. The gray value for each band was determined using the Image-J image analysis software (National Institutes of Health, Bethesda, MD, USA). The relative value of objective protein normalized to GAPDH was recorded. Each sample was repeated 3 times, and the average value was calculated.

\section{Statistical analysis}

The SPSS 13.0 statistical software (SPSS, Chicago, IL, USA) was used to process data, which are reported as means \pm standard deviation. The relationship between the expression of K-ras and miRNA21 was analyzed using Pearson's correlation analysis. $\mathrm{P}<0.05$ indicated a statistically significant difference. 


\section{RESULTS}

\section{$V E G F$ and VEGFR mRNA expression in HCC tissues in each group}

The relative expression of $V E G F$ mRNA in the model group was significantly increased $(\mathrm{P}<0.05)$ compared to that of the control group. The relative expression of $V E G F$ mRNA in group $\mathrm{C}$ was significantly lower than that of group $\mathrm{B}(\mathrm{P}<0.05)$; the relative expression of VEGFR mRNA in group $\mathrm{B}$ was significantly greater than that of group $\mathrm{A}(\mathrm{P}<0.05)$. In addition, there was no significant change in the relative expression of VEGFR mRNA between the VEGF blocking agent group and the model group $(\mathrm{P}>0.05)$. Statistical differences existed in the relative expression of VEGFR mRNA between groups $\mathrm{C}$ and $\mathrm{A}(\mathrm{P}<0.05)$ (Table 1 and Figure 3).

\begin{tabular}{|c|c|c|}
\hline Group & $V E G F 2^{-\Delta \Delta C \mathrm{t}}$ & $V E G F R 2^{-\Delta \Delta C \mathrm{t}}$ \\
\hline Control group (A) & $0.85 \pm 0.16^{\mathrm{bc}}$ & $0.78 \pm 0.13^{\text {bc }}$ \\
\hline Model group (B) & $4.9 \pm 0.988^{\mathrm{ac}}$ & $4.45 \pm 1.18^{\mathrm{a}}$ \\
\hline VEGF blocking agent group (C) & $1.93 \pm 0.39^{\mathrm{ab}}$ & $4.08 \pm 1.21^{\mathrm{a}}$ \\
\hline
\end{tabular}

Values are reported as means \pm standard deviation; $\mathrm{N}=6$. ${ }^{\mathrm{a}} \mathrm{P}<0.05 v s$ control group; ${ }^{\mathrm{b}} \mathrm{P}<0.05 v s$ model group; ${ }^{\mathrm{C}} \mathrm{P}$ $<0.05$ vs VEGF blocking agent group.
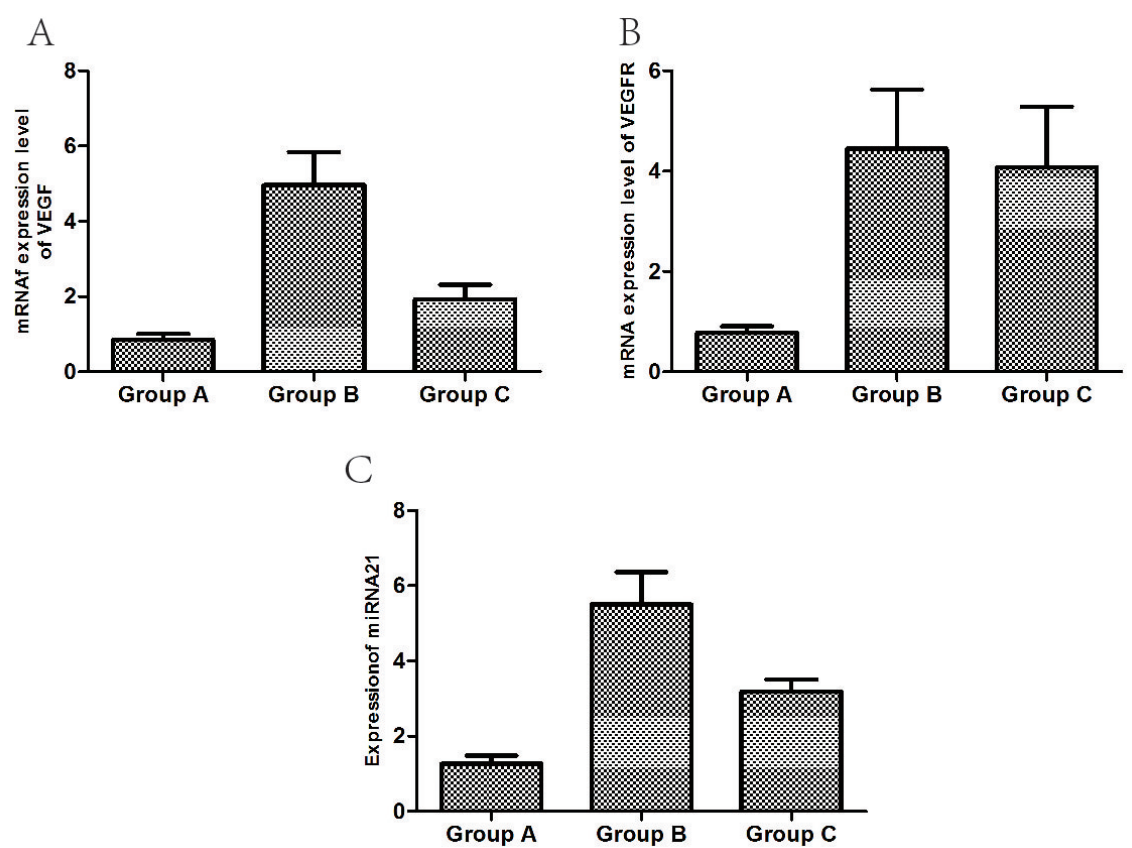

Figure 3. Detection of expression levels. Fluorescence quantitative reverse transcription polymerase chain reaction (RT-PCR) analysis was used to show the relative mRNA expression levels of VEGF (A), VEGFR (B), and miRNA21 (C) in the three groups. Group A = control group; Group B = hepatocellular carcinoma model group; Group $\mathrm{C}=$ VEGF blocking agent group. 


\section{Expression of K-ras protein in HCC tissues in each group}

Compared with that of the control group, the expression of K-ras in the HCC model group was significantly increased $(\mathrm{P}<0.05)$; the expression of $\mathrm{K}$-ras protein in the hepatocarcinoma tissues in the VEGF blocking agent group was significantly lower than that in the HCC model group $(\mathrm{P}<0.05)$; and the expression of the K-ras protein in the VEGF blocking agent group was higher than in the control group, and the differences were significant $(\mathrm{P}<$ 0.05) (Table 2 and Figure 4).

Table 2. Relative expression of K-ras protein in each group by Western blot.

\begin{tabular}{lc}
\hline Group & K-ras/GAPDH \\
\hline Control group (A) & $0.54 \pm 0.08^{\text {bc }}$ \\
Model group (B) & $0.85 \pm 0.12^{\text {ac }}$ \\
VEGF blocking agent group (C) & $0.67 \pm 0.09^{\text {ab }}$ \\
\hline
\end{tabular}

Values are reported as means \pm standard deviation; $\mathrm{N}=6$. ${ }^{\mathrm{a}} \mathrm{P}<0.05 v s$ control group; ${ }^{\mathrm{b}} \mathrm{P}<0.05 v s$ model group; ${ }^{\mathrm{C}}$ $<0.05$ vs VEGF blocking agent group.
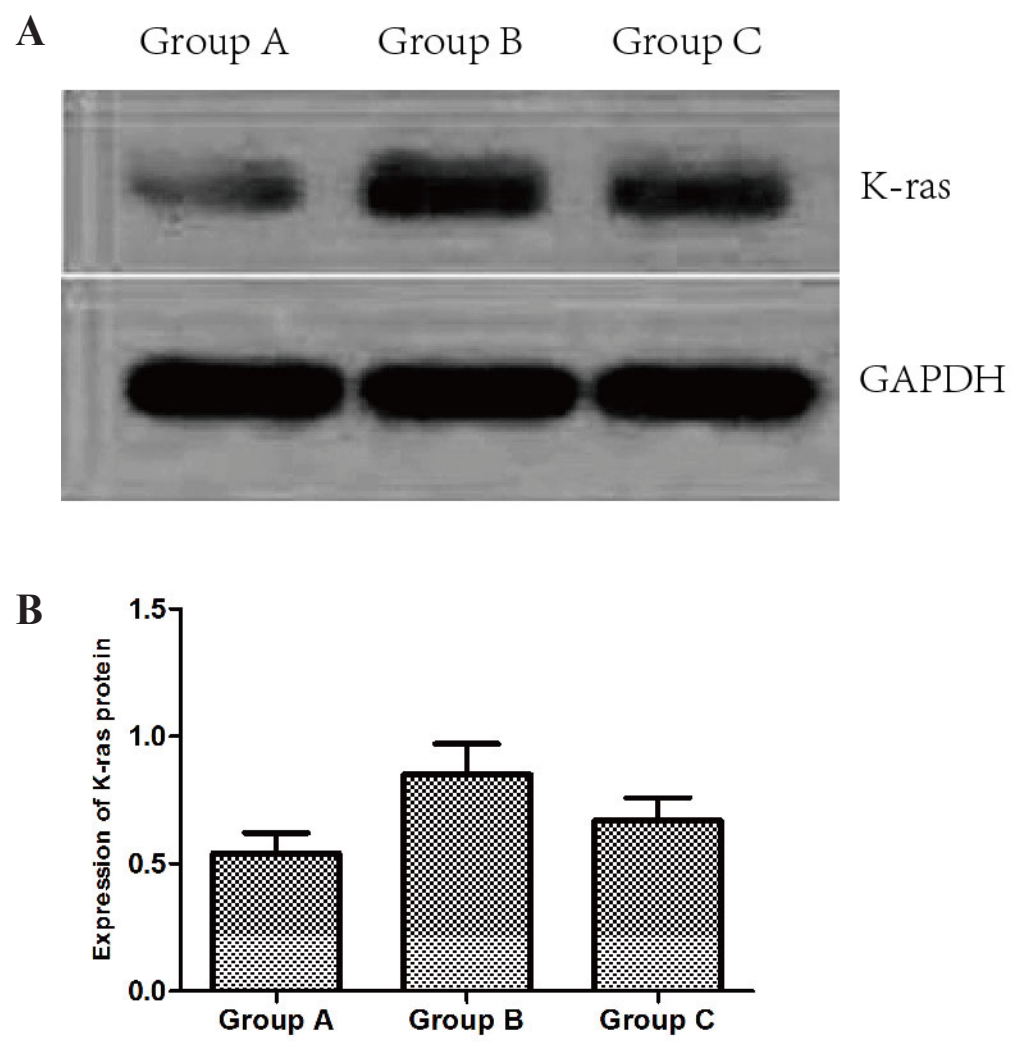

Figure 4. Western blot analysis showing the expression of the K-ras protein in the tissues of three groups. A. Western blot image. B. Quantitation of bands in A. K-ras expression was normalized to GAPDH levels. Group A= control group; Group B = hepatocellular carcinoma model group; Group C = VEGF blocking agent group. 


\section{Expression level of miRNA21 in HCC tissues of each group}

The relative expression of the miRNA21 gene in the model group was greater than that in the control group $(\mathrm{P}<0.05)$; the relative expression of the miRNA21 gene in the VEGF blocking agent group was lower than in the model group $(\mathrm{P}<0.05)$. The relative expression of the miRNA21 gene in the VEGF blocking agent group was greater than in the control group, and the differences were of statistical significance $(\mathrm{P}<0.05)$ (Table 3 and Figure 3$)$.

Table 3. Quantitation of miRNA21 expression of in each group $\left(2^{-\Delta \Delta C t}\right)$.

\begin{tabular}{lc}
\hline Group & miRNA21 $2^{-\Delta \Delta \mathrm{Ct}}$ \\
\hline Control group (A) & $1.27 \pm 0.21^{\mathrm{bc}}$ \\
Model group (B) & $5.50 \pm 0.86^{\mathrm{ac}}$ \\
VEGF blocking agent group (C) & $3.18 \pm 0.33^{\mathrm{ab}}$ \\
\hline
\end{tabular}

Values are reported as means \pm standard deviation; $\mathrm{N}=6$. ${ }^{\mathrm{a}} \mathrm{P}<0.05$ vs control group; ${ }^{\mathrm{b}} \mathrm{P}<0.05$ vs model group; ${ }^{\mathrm{P}}$ $<0.05$ vs VEGF blocking agent group.

\section{Relationship between the expression of K-ras protein and miRNA21in HCC tissues}

Pearson's correlation analysis demonstrated that the relative expression of K-ras protein in liver tissues for each experimental group was positively correlated with the relative expression of miRNA21 $(\mathrm{r}=0.913, \mathrm{P}=0.001)$.

\section{DISCUSSION}

$\mathrm{HCC}$ is one of the most common malignant tumors found across the globe. It is a multiple blood supply malignant tumor. Recent research has identified VEGF signal transduction systems closely related with cell growth, differentiation, proliferation, apoptosis, invasion, and metastasis in most eukaryotic cells. The VEGF signal transduction pathway is a tumor recurrence and metastasis-promoting pathway composed of the VEGF superfamily, the VEGFR, signal proteins, and a nuclear transcription factor (Sitohy et al., 2012; Terme et al., 2013).

VEGF is a strong angiogenesis factor in vivo, and its receptor belongs to the tyrosine kinase receptor family. The VEGF family is comprised primarily of VEGFR-1, -2, and -3 (Mehnert et al., 2010). The interaction between VEGF and its receptor activates a series of cellular signals-transduced cellular pathway that promotes the migration and proliferation of newly produced endothelial cells in vessels surrounding tumor tissues, eventually leading to the formation and proliferation of vessels (Shibuya, 2011). This study demonstrates that the relative expression of $V E G F$ and $V E G F R$ genes in the HCC model group was significantly greater than that of the control group. After application of the VEGF blocking agent, the relative expression of $V E G F$ mRNA significantly decreased, while the change of the relative expression of the VEGFR gene was not obvious compared with that of the model group. These data indicate that the VEGF-related signal pathway plays an important role in carcinogenesis, development, metastasis, and invasion.

Studies in recent years have shown that chronic hepatitis B, chronic alcoholic intoxication, and other pathogenic factors can promote overexpression of growth factors of the liver cell membrane surface such as VEGF, platelet-derived growth factor- $\beta$, and their receptors. 
The interaction of the overexpressed growth factors with their receptors activates the cell signal transduction pathway for receptor tyrosine kinases. The carboxyl residue of the tyrosine kinase receptor is phosphorylated, leading to guanine nucleotide exchange factor binding with the phosphorylated tyrosine residues, resulting in excessive activation of Ras kinase (Aravalli et al., 2008; Berasain et al., 2012). The activated Ras inhibits cell apoptosis and promotes cell survival through downstream-activated signaling pathways, and eventually leads to abnormal cellular proliferation and the formation of tumors. Ras family proteins include $\mathrm{N}-, \mathrm{H}-$, and $\mathrm{K}$-ras. K-ras is the most important signal transducer in the VEGF-related signal transduction pathway, and is also a recognized oncogene. This study suggests that the expression of K-ras in the HCC model group showed a significant increase as compared with the control group. After application of the VEGF blocking agent, the expression of K-ras protein in rat HCC tissues was significantly lower than in the HCC model group, suggesting that the abnormal expression of K-ras signal transduction protein is related to abnormal proliferation, invasion, and growth of HCC cells and to other malignant features as well.

miRNAs are recently discovered small endogenous non-protein coding RNAs. Further studies revealed that every miRNA has a host of target genes, which are involved in cell proliferation, apoptosis, tumorigenesis, and metastasis (Schmittgen, 2008; Giordano and Columbano, 2013). Recent studies have demonstrated that the expression levels of miRNAs in various tumor tissues can be up- or downregulated to varying degrees. As many miRNA target genes are involved in the signal transduction pathways of tumors, this finding indicates that miRNAs may be defined as a new group of oncogenes or tumor suppressor genes, which are closely related to the occurrence and development of tumors and which can regulate tumor growth, apoptosis, invasion, metastasis, and angiogenesis in tumor tissues (Ahmed, 2007; Lages et al., 2012). Jiang et al. (2008) found that there were 19 miRNAs, including miRNA223, -196, and -21, in HCC tissues and peficancerous tissues of patients with HCC. Research performed on miRNAs from human HCC tissues also illustrated that the expression of miRNA21 was extremely high, and this high expression was associated with the enhanced proliferation, migration, and invasion of HCC cells, and other biological malignant behaviors (Meng et al., 2007). The results of the present study demonstrated that the relative expression of the miRNA21 gene in the HCC model group was significantly higher than that of the control group, and the relative expression of miRNA21 in the VEGF blocking agent group was lower than that of the model group, indicating that higher expression of miRNA21 is closely related to HCC pathogenesis. Simultaneously, correlation analysis showed that the signal transduction K-ras protein in the VEGF-related signaling pathway was positively correlated with miRNA21, further suggesting that the VEGF/VEGFR/K-ras signaling pathway might contribute to carcinogenesis, invasion, and metastasis by regulating miRNA21 expression.

In conclusion, highly specific expression of miRNA21 controlled by the VEGF/ VEGFR/K-ras signaling pathway provided further evidence that disruption of the cancer occurrence, development, and metastasis-related signaling pathways in HCC could downregulate the expression of genes that promote the growth and metastasis of tumor cells and play anti-tumors roles, providing a multiplicity of biological therapeutic targets for HCC. In addition, due to the multiple targets and heterogeneity of miRNAs, there might be some potential regulatory mechanism loops between the VEGF/K-ras-related signaling pathways and miRNA21. However, how VEGF/K-ras-related signaling pathways and miRNA21 may affect mutual regulation remains unclear and the exact mechanisms still need further investigation. 


\section{ACKNOWLEDGMENTS}

Research supported by funding projects of the Natural Science Foundation in Henan Province (grant \#14A310003) and a Fund of High Academic Qualifications and the Scientific Research Fund of Xinxiang Medical University (grant \#2013ZD105).

\section{REFERENCES}

Ahmed FE (2007). Role of miRNA in carcinogenesis and biomarker selection: a methodological view. Expert Rev. Mol. Diagn. 7: 569-603.

Aravalli RN, Steer CJ and Cressman EN (2008). Molecular mechanisms of hepatocellular carcinoma. Hepatology 48: 2047-2063.

Berasain C, Nicou A, Garcia-Irigoyen O, Latasa MU, et al. (2012). Epidermal growth factor receptor signaling in hepatocellular carcinoma: inflammatory activation and a new intracellular regulatory mechanism. Dig. Dis. 30: 524-531.

Futakuchi M, Hirose M, Ogiso T, Kato K, et al. (1999). Establishment of an in vivo highly metastatic rat hepatocellular carcinoma model. Jpn. J. Cancer Res. 90: 1196-1202.

Giordano S and Columbano A (2013). MicroRNAs: new tools for diagnosis, prognosis, and therapy in hepatocellular carcinoma? Hepatology 57: 840-847.

Hu QY, Jiang H, Su J and Jia YQ (2013). MicroRNAs as biomarkers for hepatocellular carcinoma: a diagnostic metaanalysis. Clin. Lab. 59: 1113-1120.

Jiang J, Gusev Y, Aderca I, Mettler TA, et al. (2008). Association of microRNA expression in hepatocellular carcinomas with hepatitis infection, cirrhosis, and patient survival. Clin. Cancer Res. 14: 419-427.

Lages E, Ipas H, Guttin A, Nesr H, et al. (2012). MicroRNAs: molecular features and role in cancer. Front Biosci. 17: 2508-2540.

Mehnert JM, McCarthy MM, Jilaveanu L, Flaherty KT, et al. (2010). Quantitative expression of VEGF, VEGF-R1, VEGF-R2, and VEGF-R3 in melanoma tissue microarrays. Hum. Pathol. 41: 375-384.

Meng F, Henson R, Wehbe-Janek H, Ghoshal K, et al. (2007). MicroRNA-21 regulates expression of the PTEN tumor suppressor gene in human hepatocellular cancer. Gastroenterology 133: 647-658.

Meng QW, Li Y, Hu BS, Shao PJ, et al. (2013). Prognostic significance of serum level of vascular endothelial growth factor receptor-2 in hepatocellular carcinoma patients after transcatheter arterial chemoembolization. Zhonghua Yi Xue Za Zhi 93: 341-344.

Schmittgen TD (2008). Regulation of microRNA processing in development, differentiation and cancer. J. Cell. Mol. Med. 12: 1811-1819.

Shibuya M (2011). Vascular Endothelial Growth Factor (VEGF) and its receptor (VEGFR) signaling in angiogenesis: A crucial target for anti- and pro-angiogenic therapies. Genes Cancer 2: 1097-1105.

Sitohy B, Nagy JA and Dvorak HF (2012). Anti-VEGF/VEGFR therapy for cancer: reassessing the target. Cancer Res. 72: 1909-1914.

Terme M, Pernot S, Marcheteau E, Sandoval F, et al. (2013). VEGFA-VEGFR pathway blockade inhibits tumor-induced regulatory T-cell proliferation in colorectal cancer. Cancer Res. 73: 539-549. 